\title{
Comparison of two moldable calcium phosphate-based bone graft materials in a non- instrumented canine interspinous implantation model
}

\author{
Davide Barbieri $^{\mathrm{a}, \mathrm{b}}$, Huipin Yuan ${ }^{\mathrm{b}, \mathrm{c}, \mathrm{d}}$, Ali Sait Ismailoğlu ${ }^{\mathrm{e}}$, Joost D. de Bruijn ${ }^{\mathrm{a}, \mathrm{b}, \mathrm{f}}$ \\ ${ }^{a}$ Biomaterial Science and Technology, MIRA Institute, University of Twente, Enschede, the Netherlands \\ ${ }^{\mathrm{b}}$ Xpand Biotechnology BV, Bilthoven, the Netherlands \\ ${ }^{\mathrm{c}}$ Complex Tissue Regeneration, MERLN Institute, Maastricht University, Maastricht, the Netherlands \\ d College of Physical Science and Technology, Sichuan University, Chengdu, China \\ ${ }^{\mathrm{e}}$ NuVasive Inc., San Diego, United States \\ ${ }^{\mathrm{f}}$ Queen Mary University of London, School of Engineering and Materials Science, London, United Kingdom \\ Address correspondence to: \\ Davide Barbieri, $\mathrm{PhD}$ \\ Xpand Biotechnology BV \\ Prof. Bronkhorstlaan 10, building 48 \\ 3723 MB Bilthoven, the Netherlands \\ E-mail: davide.barbieri@xpand-biotech.com
}

Huipin Yuan, $\mathrm{PhD}$

Complex Tissue Regeneration

MERLN Institute, Maastricht University,

Maastricht, the Netherlands

E-mail: h.yuan@maastrichtuniversity.nl

Conflict of interest:

Davide Barbieri is employee of Xpand Biotechnology BV.

Huipin Yuan is employee and shareholder of Xpand Biotechnology BV.

Ali Sait Ismailoğlu is employee of NuVasive Inc.

Joost D. de Bruijn is employee and shareholder of Xpand Biotechnology BV. 


\begin{abstract}
There is a continuing search for novel synthetic materials as an alternative to autologous bone grafting. Different technologies are explored to promote bone formation, which include the addition of BioGlass ${ }^{\mathrm{TM}}$ particles in calcium phosphate (CaP) based materials and the use of surface modification in the form of submicron surface topographies. In this work we aimed at comparing the bone formation in a non-instrumented canine interspinous (IS) model of moldable formulations of a submicron surface structured tricalcium phosphate/alkylene oxide (CaP/AOC) or a tricalcium phosphate/BioGlass ${ }^{\mathrm{TM}} /$ collagen $(\mathrm{CaP} / \mathrm{BG} / \mathrm{C})$ bone graft material. Intramuscular implantation was carried out as well to evaluate soft tissue responses.

Eight mature male mongrel dogs underwent single-level, non-instrumented interspinous implantation, where the bone graft materials were implanted at either side of the spinous processes (L3-L4), with separation by the interspinous ligament ensuring comparison of both materials in each animal ( $\mathrm{n}=8$ per material). The materials were also implanted in paraspinal muscle pouches. Animals were euthanized 12 weeks after surgery and the lumbar spines excised and intramuscular implants retrieved. Un-decalcified sections were prepared for histological evaluation and histomorphometry was performed to quantify bone formation and material resorption. After 12 weeks all submicron structured CaP/AOC implants showed abundant bone formation in the (L3-L4) interspinous space (20.8 $\pm 6.8 \%$ ), while bone was not found in the $\mathrm{CaP} / \mathrm{BG} / \mathrm{C}$ implants $(0 \pm 0 \%)$. Intramuscularly, the $\mathrm{CaP} / \mathrm{AOC}$ material triggered significant bone formation $(12.0 \pm 7.8 \%)$, while $\mathrm{CaP} / \mathrm{BG} / \mathrm{C}$ did not form any bone. In both the spinal and muscular sites, resorption of the $\mathrm{CaP} / \mathrm{AOC}$ material was evident by a decrease in Feret diameter of the $\mathrm{CaP}$ granules as well as in their histological surface compared to the starting material, while $\mathrm{CaP} / \mathrm{BG} / \mathrm{C}$ material had a milder resorption. This study shows that a submicron surface structured $\mathrm{CaP} / \mathrm{AOC}$ bone graft material has superior bone forming properties in both an interspinous implantation model and intramuscularly, as compared to a $\mathrm{CaP} / \mathrm{BG} / \mathrm{C}$ bone graft material.
\end{abstract}

Keywords: Bone graft; Calcium phosphate; Submicron structured; Bioglass; Osteoinduction; Spinal fusion. 


\section{Introduction}

Many conditions that cause pain and instability of the vertebral column (e.g. degenerative disc disease, scoliosis and trauma) require spinal fusion using bone graft materials [1]. Since bone formation is crucial in these interventions, the ability of the graft material to regenerate bone should be considered during surgical planning. Autologous bone is currently the gold standard bone graft material but its disadvantages (limited availability, donor site morbidity and post-operative pain) have motivated researchers to look for alternatives [1].

Calcium phosphate $(\mathrm{CaP})$ ceramics mimic the chemistry of bone mineral and allow precipitation of bioactive bone-like apatite from body fluids on their surface, which facilitates the infiltration of the host's tissues and cells ultimately leading to bone formation [2]. They are therefore the most often used synthetic biomaterials in bone repair [3-7], although their bone regenerative potential is limited due to the lack of osteogenic and osteoinductive properties. To improve the bone forming ability of $\mathrm{CaP}$ ceramics, osteogenic cells may be introduced into synthetics through cell therapy techniques (e.g. bone marrow aspirate) [8], while growth factors (e.g. BMPs and PDGF) [9] or gene-transfected growth factor-producing cells [10] could also be used. A combination of these approaches may produce a material with comparable bone forming potential to autograft, but it would still not be the ideal solution because of high costs and complex manufacturing that often lead to not 'off-the-shelf' products. A promising way to improve the bone forming ability of $\mathrm{CaP}$ ceramics is by controlling their physicochemical properties such as geometry [11], surface microstructure [12] and chemistry [13]. Surface structural features have particularly been shown essential for enhanced bone formation. For instance, the absence of micropores smaller than $10 \mu \mathrm{m}$ led to decreased bone formation of CaP ceramics [12, 14], while decreasing the surface topographical features showed that resorbable submicron structured tricalcium phosphate (TCP) ceramics are osteoinductive in ectopic sites [5, 15] and have enhanced bone formation in orthotopic sites [16] and a spinal environment [17]. Next to physical modifications of the surface structure, the introduction of ions such as silicon has also been reported to improve the bone forming ability of $\mathrm{CaP}$ ceramics $[18,19]$. Enhanced formation of bone-like apatite and the release of ions (i.e. $\mathrm{Ca}^{2+}, \mathrm{Na}^{+}$and $\mathrm{Si}^{4+}$ ) are thought to enhance bone formation of $\mathrm{CaP}$ ceramics [18] combined with bioactive glasses such as BioGlass ${ }^{\mathrm{TM}}$ [20].

The objective of the present study was to employ a non-instrumented canine interspinous (IS) implantation model to compare two commercially available moldable synthetic bone graft materials based on either, a surface microstructuring technology (AttraX ${ }^{\circledR}$ Putty) or a BioGlass ${ }^{\mathrm{TM}}$ based technology (Vitoss ${ }^{\mathrm{TM}}$ BA). Both materials were also implanted intramuscularly to evaluate soft tissue responses. 


\section{Materials and methods}

Bone graft materials and characterization

A calcium phosphate/alkylene oxide copolymer (CaP/AOC) putty material (AttraX Putty ${ }^{\circledR}$, NuVasive Inc., San Diego, USA) and a CaP/BioGlass ${ }^{\mathrm{TM}} /$ collagen $(\mathrm{CaP} / \mathrm{BG} / \mathrm{C})$ composite material (Vitoss ${ }^{\mathrm{TM}}$ BA, Orthovita Inc./Stryker Corp., Kalamazoo, USA) were obtained from the manufacturers. The CaP/AOC was ready for use, while $\mathrm{CaP} / \mathrm{BG} / \mathrm{C}$ was provided in two separated components, BioGlass ${ }^{\mathrm{TM}}$ granules and a CaP/collagen foam strip. The CaP granules were extracted from the AOC and collagen strip by placing the materials in sinter oven (P320, Nabertherm, Lilienthal, Germany) at $800^{\circ} \mathrm{C}$ for three hours and were then characterized. Prior burning out, the samples were weighed to allow the determination of their composition (by weight) in CaP, BG and organic phases. The chemistry of the CaP granules was analyzed via X-ray diffractometry (XRD; MiniFlex II, Rigaku, Tokyo, Japan), while scanning electron microscopy (SEM; XL30, ESEM-FEG, Philips, Eindhoven, the Netherlands) was employed to observe the surface structure. Granules of both materials were also analyzed with mercury intrusion porosimetry (Micromeritics Instrument Corporation, Norcross, GA, USA) to obtain information on total porosity (i.e. the volume percentage of pores in the materials), macroporosity (i.e. the volume percentage of pores greater than, or equal, to $10 \mu \mathrm{m}$ in the materials), microporosity (i.e. the volume percentage of pores smaller than $10 \mu \mathrm{m}$ in the materials), pore size distribution in the ceramic strut and specific surface area. The organic component of $\mathrm{CaP} / \mathrm{BG} / \mathrm{C}$ is declared as collagen type I by the supplier, and is a wellknown material, thus was not further analyzed. On the contrary, AOC formulation is not precisely claimed by the commercial supplier and is described in the patent US 8,124,687 B2. Therefore, CaP/AOC putty was immersed in chloroform for 12 hour to obtain a supernatant, which was then separated from the CaP granules via decantation. The obtained solution was then placed in an oven at $40^{\circ} \mathrm{C}$ overnight, under vacuum extraction, to finally get a sticky paste-like material (i.e. the AOC component). This paste was subjected to proton nuclear magnetic resonance spectroscopy $\left({ }^{1 \mathrm{H}} \mathrm{NMR}\right.$; Bruker Ascend 400/Avance III, Bruker, Leiderdorp, the Netherlands); d-chloroform, $400 \mathrm{MHz}$ ) and attenuated total reflectance Fourier transform infra-red spectroscopy (ATR-FTIR; Spectrum Two, Perkin Elmer, Groningen, the Netherlands; ZnSe crystal) to determine its chemistry.

\section{Surgical procedure, necropsy and tissue collection}

A canine interspinous (IS) implantation model [17] was used to compare bone formation with the two synthetic bone graft materials. The model is a modification from Muschler et al. [21, 22] in that instrumentation was not 
used to immobilize the spine, while the lamina and facet joints were left intact. Soft tissue response to the synthetic bone substitute materials was determined after intramuscular implantation [5, 17, 23].

Surgery was performed on eight adult dogs (mongrel, male, 10-15 kg, 1-2 year old) at the facility of Chengdu Dossy Experimental Animals Co. Ltd. (Chengdu, China), which is licensed to perform animal experiments (License no. SYXK (CHUAN) 2014-189, issued by the management committee for animal experiments of Sichuan province). All surgeries were conducted under general anesthesia by an abdominal injection of sodium pentobarbital (30 mg/kg body weight; Merck, Darmstadt, Germany). After shaving and cleaning the surgical site with iodine, longitudinal skin and median fascial incisions were made. The paraspinal muscles were retracted to expose the spinous processes at the L3 and L4 levels. Tissues at both sides of the spine were separated from the intra- and supra-spinous ligaments to create two implantation beds next to the L3 and L4 spinous processes. After superficial decortication of either side of the spinous processes with a rasp to create punctate bleeding, $5 \mathrm{cc}$ of each graft material (Figure 1) was placed at either side of the spinal ridge to bridge the two spinous processes according to a randomization schedule. CaP/AOC was used as received (Figure 1) and shaped to fit the defect, while $\mathrm{CaP} / \mathrm{BG} / \mathrm{C}$ was prepared according to the manufacturer's instructions. In short, one gram of Bioglass ${ }^{\mathrm{TM}}$ granules were loaded onto the surface of the TCP/collagen foam strip $(10 \mathrm{cc})$, which was then wet with $9 \mathrm{ml}$ physiological saline and mixed thoroughly to uniformly combine the components. Half of the prepared $\mathrm{CaP} / \mathrm{BG} / \mathrm{C}$ composite (i.e. $5 \mathrm{cc}$, Figure 1) was shaped into the spinous defect, while one cc was used for intramuscular implantation as described later. Once both materials were placed in the spinous defects, the muscles from both sides were tightly closed with silk suture. Subsequently, two paraspinal muscle pouches were created with blunt separation at least $3 \mathrm{~cm}$ away from the spinal bone. One cc of CaP/AOC putty or one cc of $\mathrm{CaP} / \mathrm{BG} / \mathrm{C}$ composite was implanted in each muscle pouch and sealed with silk suture. The wound was finally closed layer by layer with silk sutures. Following surgery, the animals were intramuscularly given buprenorphine (0.1 mg per animal; Merck) for two days to relieve pain and penicillin (40 mg/kg; Merck) for three days to prevent infection. The animals were allowed full weight bearing and received a normal diet. Calcein $(10 \mathrm{mg} / \mathrm{kg}$ body weight; Sigma-Aldrich, Steinheim, Germany) was intravenously injected six weeks after implantation to monitor the onset of bone formation. Animals were euthanized at 12 weeks by a barbiturate overdose and the lumbar spines excised and intramuscular implants were harvested with surrounding tissues. 


\section{Histology and histomorphometry}

The explants were trimmed, fixed in $4 \%$ formaldehyde (Sigma-Aldrich) and dehydrated through a series of ethanol (Sigma-Aldrich) prior to embedding in methyl methacrylate (L.T.I., Bilthoven, the Netherlands) using standard techniques. Non-decalcified sections were made using a diamond saw (SP-1600; Leica, Mannheim, Germany) and stained with $1 \%$ methylene blue (Sigma-Aldrich) and $0.3 \%$ basic fuchsin (Sigma-Aldrich) for light microscopy and histomorphometric analysis. Fluorescent microscopy was performed on unstained sections using a FITC Texas Red filter (band-pass mirror wavelengths of 510-555 nm and 585-665 nm; Nikon, Tokyo, Japan). The spines were sectioned in the coronal plane, while cross sections of the intramuscular samples were made. Histomorphometric analysis was done on scanned stained slides (Dimage Scan Elite5400 II, model AF5400-2; Konica Minolta, Tokyo, Japan). Bone formation was quantified using the histogram function in Adobe Photoshop (CS5, v12; Adobe Systems Benelux BV, Amsterdam, the Netherlands). The area adjacent to and between both (L3-L4) spinous processes was selected as region of interest (ROI) and the number of pixels was read. The ROI for the intramuscular samples was determined as the area of material encapsulated by a thin connective tissue layer. After determining the ROI, material and bone were pseudo-colored and pixels read as M and $\mathrm{B}$ respectively. The area percentage of bone in the available space was calculated as B*100/(ROI-M). Bone contact with the surface of the granules was determined as the ratio $100 * \mathrm{P}_{\mathrm{B}} / \mathrm{P}_{\mathrm{G}}$, where $\mathrm{P}_{\mathrm{B}}$ is the perimeter of bone in direct contact with the surface of the granules, while $\mathrm{P}_{\mathrm{G}}$ is the perimeter of all the granules in the ROI. The perimeters were measured using the 'analyze/measure' function in ImageJ (v1.43u, NIH, Bethesda, USA). The in vivo resorption rate was assessed via measuring the change in the histological area (i.e. the amount of pixels belonging to $\mathrm{CaP}$ and $\mathrm{BG}$ components, normalized to the ROI) in the explants. For this latter measurement, sections made from MMA blocks containing the starting amounts of $\mathrm{CaP}$ and $\mathrm{CaP} / \mathrm{BG}$ in the two grafts (after burning AOC and collagen out at $800^{\circ} \mathrm{C}$ for three hours) were used as time zero controls.

A further demonstration of material resorption was given by comparing the average maximum Feret diameters of the $\mathrm{CaP}$ granules prior to and after implantation. For this measurement, sections made from MMA blocks containing the starting ceramic granules were used as time zero controls. Before extracting the diameters, all images (at least three slides of each sample) were pre-processed to remove background noise and objects of no interest (e.g. bone tissue) using Adobe Photoshop. Afterwards, by using ImageJ, the images were converted into a binary format and analyzed using the 'analyze particles' algorithm to finally measure the maximum Feret diameters. The total number of granules measured was about 2000 and the diameters were expressed as mean and standard deviation. Diameters were taken of the longest and shortest length of the granules, provided that 
they were perpendicular with each other. However, they could be measured only for CaP/AOC samples because severe fragmentation of the $\mathrm{CaP}$ granules in $\mathrm{CaP} / \mathrm{BG} / \mathrm{C}$ rendered it impossible to adequately determine their diameters.

\section{Statistical analysis}

Statistical analysis was performed using the two tail $t$-test with significance defined as $\mathrm{p}<0.05$. The power of both spine and muscular experiments was determined with a post-hoc power analysis (two-tail $t$-test for difference in mean) using the freeware $\mathrm{G}^{*}$ Power software [24].

\section{Results}

\section{Characterization of the bone graft materials}

After burning out AOC and collagen, the content by weight of each component in the two grafts was determined (Table 1). X-ray diffraction showed that the ceramic component in CaP/AOC was comprised of tricalcium phosphate (96\% wt.) with a minor phase of hydroxyapatite (Figure 2a, Table 1), while the ceramic component in $\mathrm{CaP} / \mathrm{BG} / \mathrm{C}$ was pure tricalcium phosphate. Scanning electron microscopy revealed that the CaP of both materials had a different surface topography and consisted of grains that were different in size (Figures $2 \mathrm{c}$ and $2 \mathrm{~d}$ ). The ceramic from CaP/AOC had submicron-sized grains (0.8-1.1 micrometer) and pores (0.3-1.1 micrometer), while the grain and micropore size of the ceramic in $\mathrm{CaP} / \mathrm{BG} / \mathrm{C}$ were $1.9-3.1$ micrometer and $0.5-4.5$ micrometer, respectively. These findings were corroborated by the mercury intrusion data (Figure $2 \mathrm{~b}$ and Table 1), which demonstrated that the ceramic phase of $\mathrm{CaP} / \mathrm{AOC}$ had a significant larger component of submicron-sized pores than the ceramic in $\mathrm{CaP} / \mathrm{BG} / \mathrm{C}$. As already mentioned earlier, collagen type $\mathrm{I}$ is the organic component of $\mathrm{CaP} / \mathrm{BG} / \mathrm{C}$ material (Table 1). The binder of $\mathrm{CaP} / \mathrm{AOC}$ was identified (via ${ }^{1 \mathrm{H}} \mathrm{NMR}$ and FTIR) as a mixture, or copolymer, of poly(ethylene glycol) (PEG) and poly(propylene glycol) (PPG) (Table 1), confirming that AOC is a Poloxamer-based formulation as already published elsewhere [25].

\section{Surgery}

Both materials were moldable and could be handled in an acceptable fashion during implantation. However, during the preparation of $\mathrm{CaP} / \mathrm{BG} / \mathrm{C}$ composite, it was observed that it decreased its volume of about $30 \%$ when it was hydrated with physiological saline. Afterwards, we could cut the obtained $\mathrm{CaP} / \mathrm{BG} / \mathrm{C}$ composite into a 5 cc sample (for the spine site, Figure 1) and a $1 \mathrm{cc}$ sample for the intramuscular implantation. The surgical 
procedure was uneventful and no post-operative complications were observed. One animal died after nine weeks due to causes unrelated to the experiment and was excluded from the study.

\section{Histology and histomorphometry of the interspinous (IS) implants}

After 12 weeks of implantation, the CaP/AOC implants had largely retained their shape and were larger in volume as compared to the $\mathrm{CaP} / \mathrm{BG} / \mathrm{C}$ implants that seemed to have collapsed (Figure 3). Formation of new bone tissue was observed throughout the $\mathrm{CaP} / \mathrm{AOC}$ implants $(20.8 \pm 6.8 \%$ in the available space of the ROI, with a bone/granule contact of $24.1 \pm 5.9 \%$ ), while it was absent in $\mathrm{CaP} / \mathrm{BG} / \mathrm{C}$ implants. Bone was not homogenously distributed between L3-L4 in the CaP/AOC implants and solid spinal fusion was therefore not achieved (Figure 3). In particular, more bone tissue formed in the regions next to the spinous processes (Figure 4) while less was seen in the central area between both processes. In this central area, fibrous cartilage tissue formation was often detected (Figure 5). Interestingly, bone formation also occurred far away from the host bone bed of the CaP/AOC implants. When observed in detail, the regions closest to the spinous processes presented osteoid, mineralized bone and bone marrow (Figure 4), while further away from the host bone bed also fibrous cartilage was observed (Figure 5a).

Resorption of the ceramic granules in CaP/AOC implants was more pronounced in sites distant from the host bone as indicated by the presence of small fragments taken up by giant cells (Figures 5 and 6). Quantitative measurements on the $\mathrm{CaP}$ granules showed a $50.8 \%$ and $54.9 \%$ reductions in their histological area and Feret diameter, respectively, compared to the pre-implantation samples (Table 2). These results confirm that resorption of the ceramic granules in CaP/AOC spine explants occurred over a time span of 12 weeks.

A limited amount of bone had formed between the spinous processes in $\mathrm{CaP} / \mathrm{BG} / \mathrm{C}$ implants $(0 \pm 0 \%)$. Even close to the host bone bed, new bone formation was sporadically seen (Figure 7a). Fragments of TCP granules were seen phagocytized by giant cells and were sometimes embedded in areas of new bone formation (Figure 7b). Fibrous tissue was usually seen infiltrating between the granules of BioGlass ${ }^{\mathrm{TM}}$ and TCP fragments (Figures 3 and 8). The severe fragmentation of the $\mathrm{CaP} / \mathrm{BG} / \mathrm{C}$ implants may have led to their collapse in the surgical site, and hindered the ability to quantify its resorption rate via the Feret diameter. However, it was possible to measure the histological area of the TCP material (i.e. remaining granules and fragmented residuals) and BioGlass $^{\mathrm{TM}}$ fragments. In particular, the area of the TCP and BioGlass ${ }^{\mathrm{TM}}$ components decreased by $37.6 \%$ and $32.9 \%$ respectively (Table 2), indicating that resorption of TCP and dissolution of BioGlass ${ }^{\mathrm{TM}}$ particles occurred after 12 weeks implantation. 
Fluorescence microscopy showed a calcein label in the host bone (i.e. the spinous processes) and in the $\mathrm{CaP} / \mathrm{AOC}$ and $\mathrm{CaP} / \mathrm{BG} / \mathrm{C}$ implants (Figure 9a). Calcein labels were mainly observed in areas of new bone formation near the host bone bed in the $\mathrm{CaP} / \mathrm{AOC}$ implants (Figures 9a and 9b). In the $\mathrm{CaP} / \mathrm{BG} / \mathrm{C}$ implants, calcein labels were found throughout the implantation area (Figure 9a), where it was uniquely related to the surface apatite layer formed on BioGlass ${ }^{\mathrm{TM}}$ granules (Figure 9c). This indicates that bone formation in the $\mathrm{CaP} / \mathrm{AOC}$ implants and surface apatite formation on BioGlass ${ }^{\mathrm{TM}}$ granules of the $\mathrm{CaP} / \mathrm{BG} / \mathrm{C}$ implants started before six weeks.

\section{Tissue response to the intramuscular implants}

CaP/AOC: At harvest, a thin connective tissue layer encapsulated the CaP/AOC explants without clear signs of an inflammatory reaction. Histological examination of the explants showed the presence of soft tissues, bone and $\mathrm{CaP}$ ceramic granules (Figure 10a). Areas of de novo bone formation occurred mainly in the core of the explants and the amount of newly formed bone varied among the samples. Quantitatively, $12.0 \pm 7.8 \%$ mineralized bone tissue was seen in the available space of the ROI (i.e. the space between the ceramic granules), while bone contact with the granules was $21.9 \pm 7.1 \%$ (Table 2). The polymer carrier (i.e. $\mathrm{AOC}^{\circledR}$ ) was not observed in any of the explants and resorption of the ceramic component was evident by the presence of multi-nucleated cells and small ceramic fragments in surrounding phagocytes. Resorption of the ceramic granules varied with their location within the implants. At sites where only fibrous tissues were present (Figures 10b and 10c), small fragments detached from the ceramic bodies (Figure 10b) and were phagocytized by macrophages and foreign body giant cells (Figure 10c). In areas where bone had formed (Figures 10d and 10e), the surface of ceramic granules was covered by newly formed bone and the resorption was less pronounced (Figure 10d), and giant cells were phagocytosing ceramic fragments (Figure 10e). Resorption of the ceramic occurred in areas of bone remodelling, suggesting cell mediated resorption of the ceramic. The pronounced in vivo resorption of the ceramic component in $\mathrm{CaP} / \mathrm{AOC}$ observed histologically was quantitatively corroborated by a significant decrease of the area $(-39.3 \%)$ and Feret diameter $(-47.8 \%)$ of the granules when compared to the starting baseline.

CaP/BG/C: At harvest, a soft tissue capsule was observed around the $\mathrm{CaP} / \mathrm{BG} / \mathrm{C}$ explants, without clear signs of inflammation. Although properly mixed during implant preparation and placement, the BioGlass ${ }^{\mathrm{TM}}$ granules were mainly present in the core of the explants (Figure 11a) and bone was never observed. The available space between the TCP and BioGlass ${ }^{\mathrm{TM}}$ granules was infiltrated by fibrous tissues (Figures $11 \mathrm{~b}$ and 11c) and the 
collagen component of $\mathrm{CaP} / \mathrm{BG} / \mathrm{C}$ could not be detected. Foreign body giant cells were seen colonizing the granules and mineralization occurred on BioGlass ${ }^{\mathrm{TM}}$ as suggested by the presence of a dark red layer of basic fuchsin stain (Figures 11b and 11c). Similarly to what discussed earlier, fragmentation of the CaP component prevented quantitative determination the Feret diameter, but a $20.9 \%$ decrease of the histological area was measured. Further, the histological area of BioGlass ${ }^{\mathrm{TM}}$ particles had a $26.3 \%$ decrease over the implantation period.

The 6-week fluorescent signal was not observed in any of the CaP/AOC groups, while it was seen in the $\mathrm{CaP} / \mathrm{BG} / \mathrm{C}$ implants (data not provided). As fluorescence was confined to the surface of BioGlass ${ }^{\mathrm{TM}}$ granules, it suggests the formation of a surface apatite layer. These observations furthermore indicate that intramuscular bone formation did not start before six weeks in the $\mathrm{CaP} / \mathrm{AOC}$ implants.

\section{Discussion}

In this study, we evaluated two moldable CaP-based bone graft materials in a non-instrumented canine interspinous model and intramuscularly over a 12 weeks implantation period. The bone forming potential of the materials was either 'enhanced' by creating a submicron surface topography (i.e. in CaP/AOC) or by adding BioGlass ${ }^{\mathrm{TM}}$ particles (i.e. in $\mathrm{CaP} / \mathrm{BG} / \mathrm{C}$ ). Clear performance differences were observed between both material types. Firstly, considerable bone formation and implant resorption was observed with the submicron structured $\mathrm{CaP} / \mathrm{OAC}$ implants in the spine model, while negligible bone formation and severe fragmentation was seen with the $\mathrm{CaP} / \mathrm{BG} / \mathrm{C}$ implants. Secondly, although both materials showed a mild inflammatory response after intramuscular implantation, de novo bone formation was seen in all CaP/AOC implants while only fibrous tissue infiltration was seen in the $\mathrm{CaP} / \mathrm{BG} / \mathrm{C}$ implants.

The ability of submicron structured ceramic materials such as $\mathrm{CaP} / \mathrm{AOC}$ to give rise to heterotopic bone formation has been reported before $[5,11-16]$ and is not a new finding. This material property may also have contributed to the meaningful bone formation of $\mathrm{CaP} / \mathrm{AOC}$ observed in the non-instrumented spinal site since the $\mathrm{CaP} / \mathrm{BG} / \mathrm{C}$ material was unable to form bone. Muschler et al. reported that providing instrumentation and decortication of the lamina and facet joints in a similar spinal fusion model in mongrel dogs is ineffective to obtain fusion upon implantation of a collagen ceramic composite graft material, even when mixed with cancellous bone graft or autologous bone marrow [21, 22]. These studies also showed that spinal fusion is challenging in dog interspinous models because it was not always reached even when using the golden standard autograft in presence of instrumentation and decortication [21, 22]. 
Although in our study fusion was also not observed, the presence of cartilaginous tissue in the center of the fusion mass with $\mathrm{CaP} / \mathrm{AOC}$ (Figure 5) is indicative of mechanical instability, which is known to hamper bone formation [26, 27]. It is probable that a less sensitive model to the one we used, i.e. using instrumentation and decorticating the lamina and facet joints as done by Muschler et al. [21, 22] may have allowed fusion to occur with this material.

In this study the $\mathrm{CaP}$ component of the two composites slightly differed since traces of HA were present in the inorganic component of $\mathrm{CaP} / \mathrm{AOC}$ (Figure 2a, Table 1), while pure TCP was found in the $\mathrm{CaP}$ component of $\mathrm{CaP} / \mathrm{BG} / \mathrm{C}$. The effects of these chemical differences on bone formation may have been minor compared to the potentially larger role of the surface structural dimension. In fact, as recently suggested by Davison et al. (2015) in a study testing the influence of several $\mathrm{CaP}$ material parameters (surface microstructure, macrostructure and surface chemistry), the microstructural dimensions were reported to be the most critical factors promoting bone formation [28]. The CaP phase in both graft materials contained micropores (Figure $2 \mathrm{c}$ and $2 \mathrm{~d}$ ) with similar microporosity, but the granules in $\mathrm{CaP} / \mathrm{AOC}$ had significantly larger fraction of sub-micron porosity (Figure $2 \mathrm{~b}$ and Table 1). Only the composite containing sub-micron structured material triggered instructive bone formation (Figures 10 and 11), suggesting that not only the presence of micropores but also their dimension plays a major role in CaP-directed bone formation $[5,15,17]$. It is well known that $\mathrm{CaP}$ ceramics can degrade via both chemical dissolution and cell-mediated resorption [29]. Intramuscularly, the latter phenomenon appeared histologically evident in CaP/AOC and less in CAP/BG/C (Figures 10 and 11), which suggests a possible influence of the sub-micron structured surface (Figure 2c) on the activity of phagocytes [28-30]. This would be in agreement with the findings of Davison et al. (2014) who reported that cell-mediated resorption of biomaterials and osteoclastogenesis is a prelude to material-directed bone formation [30].

Surface mineralization and silicon ion release are reported to enhance the bioactivity of BioGlass ${ }^{\mathrm{TM}}[19,20,31]$. Although we did observe in vivo surface mineralization on BioGlass ${ }^{\mathrm{TM}}$ granules in CaP/BG/C (Figure 9), no signs of osteoinduction were detected intramuscularly. In the spine the material was severely fragmented and also showed negligible bone formation. Similar disappointing results were reported by Walsh et al. (2013), who implanted $\mathrm{CaP} / \mathrm{BG} / \mathrm{C}$ combined with a bone marrow aspirate in a rabbit posterolateral spinal fusion model for up to 26 weeks and did not see any bone formation in the middle of the fusion mass [32]. Conversely, Epstein (2009) reported successful fusion in humans when the TCP component of $\mathrm{CaP} / \mathrm{BG} / \mathrm{C}$ was implanted in the instrumented posterolateral spine [33]. It should be noted that in the study of Epstein (2009), TCP was used in a large volume (30 cc granules), mixed with bone marrow aspirate and combined with the same amount of autograft. Similarly, 
when the same TCP granules were combined with autogenous BMA, it was reported to lead to high fusion rates in human posterior cervical spine [34], which suggests the need for autologous bone and osteogenic elements to support and enhance the biological activity of the TCP component in $\mathrm{CaP} / \mathrm{BG} / \mathrm{C}$ [32-34]. As a result, this may explain why $\mathrm{CaP} / \mathrm{BG} / \mathrm{C}$ was not efficacious in this study.

Within the limits of this study, the submicron structured CaP/AOC implants supported bone formation in the canine non-instrumented interspinous implantation model and showed bone induction after intramuscular implantation. Bone formation was not sufficient to achieve a solid fusion, which is likely the result of the noninstrumented nature of the model [26]. The bone forming potential of $\mathrm{CaP} / \mathrm{BG} / \mathrm{C}$ implants was limited in the spine which is likely due to the collapse and severe fragmentation of the implant either during implant preparation or after surgical placement and post-operative movement.

\section{Conclusions}

The results of this study show that a submicron surface structured CaP/AOC bone graft material has superior bone forming properties in both an interspinous implantation model as compared to a CaP/BG/C bone graft material. It also shows that the $\mathrm{CaP} / \mathrm{AOC}$ material has osteoinstructive properties, which could have aided in the bone formation shown in the spine. Further investigation is warranted to verify the link between ectopic and orthotopic bone formation and the influence of (micro) motion on bone formation in this model.

\section{References}

[1] Grabowski G, Cornett CA. Bone graft and bone graft substitutes in spine surgery: current concepts and controversies. J Am Acad Orthop Surg (2013) 21:51-60.

[2] Cornell CN. Osteoconductive materials and their role as substitutes for autogenous bone grafts. Orthop Clin North Am (1999) 30:591-8.

[3] El-Ghannam A. Bone reconstruction: from bioceramics to tissue engineering. Expert Rev Med Devices (2005) 2:87-101.

[4] Chai YC, Carlier A, Bolander J, et al. Current views on calcium phosphate osteogenicity and the translation into effective bone regeneration strategies. Acta Biomater (2012) 8:3876-87.

[5] Yuan H, Fernandes H, Habibovic P, et al. Osteoinductive ceramics as a synthetic alternative to autologous bone grafting. Proc Natl Acad Sci USA (2010) 107:13614-9. 
[6] Frayssinet P, Trouillet JL, Rouquet N, et al. Osseointegration of macroporous calcium phosphate ceramics having a different chemical composition. Biomaterials (1993) 14:423-9.

[7] Blokhuis TJ, Termaat MF, den Boer FC, et al. Properties of calcium phosphate ceramics in relation to their in vivo behavior. J Trauma (2000) 48:179-86.

[8] Shen FH, Samartzis D, An HS. Cell technologies for spinal fusion. Spine J (2005) 5:231S-9S.

[9] Glassman SD, Howard JM, Sweet A, et al. Complications and concerns with osteobiologics for spine fusion in clinical practice. Spine (Phila Pa 1976) (2010) 35:1621-8.

[10] Kimelman Bleich N, Kallai I, Lieberman JR, et al. Gene therapy approaches to regenerating bone. Adv Drug Deliv Rev. (2012) 64:1320-30.

[11] Ripamonti U, Crooks J, Kirkbride AN. Sintered porous hydroxyapatites with intrinsic osteoinductive activity: geometric induction of bone formation. S Afr J Sci (1999) 95: 335-43.

[12] Yuan H, Kurashina K, de Bruijn JD, et al. A preliminary study on osteoinduction of two kinds of calcium phosphate ceramics. (1999) Biomaterials 26:1799-806.

[13] Kurashina K, Kurita H, Wu Q, et al. Ectopic osteogenesis with biphasic ceramics of hydroxyapatite and tricalcium phosphate in rabbits. Biomaterials (2002) 23:407-12.

[14] Yamasaki H, Sakai H. Osteogenic response to porous hydroxyapatite ceramics under the skin of dogs. Biomaterials (1992) 13:308-12.

[15] Zhang J, Luo X, Barbieri D, et al. The size of surface microstructures as an osteogenic factor in calcium phosphate ceramics. Acta Biomater (2014) 10:3254-63.

[16] Habibovic P, Yuan H, van den Doel M, et al. Relevance of osteoinductive biomaterials in a critical-sized orthoepdic defect. J Orthop Res (2006) 24:867-76.

[17] Duan R, Barbieri D, Luo X, Weng J, et al. Submicron-surface structured tricalcium phosphate ceramic enhances the bone regeneration in canine spine environment. J Orth Res (2016) DOI: 10.1002/jor.23201.

[18] Bohner M. Silicon-substituted calcium phosphates - a critical view. Biomaterials (2009) 30:6403-6.

[19] Kaur G, Pandey OP, Singh K, et al. A review of bioactive glasses: Their structure, properties, fabrication, and apatite formation. J Biomed Mater Res A (2013) DOI: 10.1002/jbm.a.34690.

[20] Gerhardt LC, Boccaccini AR. Bioactive glass and glass-ceramic scaffolds for bone tissue engineering. Materials (2010) 3:3867-910.

[21] Muschler GF, Negami S, Hyodo A, et al. Evaluation of collagen ceramic composite graft materials in a spinal fusion model. Clin Orthop Relat Res (1996) 328:250-60. 
[22] Muschler GF, Hyodo A, Manning T, et al. Evaluation of human bone morphogenetic protein 2 in a canine spinal fusion model. Clin Orthop Relat Res (1994) 308:229-40.

[23] Yuan H, van Blitterswijk CA, de Groot K, et al. A comparison of bone formation in biphasic calcium phosphate (BCP) and hydroxyapatite (HA) implanted in muscle and bone of dogs at different time periods. J Biomed Mater Res A (2006) 78:139-47.

[24] Faul F, Erdfelder E, Lang AG, et al. G*Power 3: a flexible statistical power analysis program for the social, behavioral, and biomedical sciences. Behav Res Methods (2007) 39:175-191.

[25] Magyar CE, Aghaloo TL, Atti E, Tetradis S. Ostene, a new alkylene oxide copolymer bone hemostatic material, does not inhibit bone healing. Neurosurgery (2008) 63:373-84.

[26] Matsumoto T, Toyoda H, Dohzono S, Yasuda H, et al. Efficacy of interspinous process lumbar fusion with recombinant human bone morphogenetic protein-2 delivered with a synthetic polymer and $\beta$-tricalcium phosphate in a rabbit model. Eur Spine J (2012) 21:1338-45.

[27] Yokota H, Leong DJ, Sun HB. Mechanical loading: bone remodeling and cartilage maintenance. Curr Osteoporos Rep (2011) 9:237-42.

[28] Davison NL, Su J, Yuan H, et al. Influence of surface microstructure and chemistry on osteoinduction and osteoclastogenesis by biphasic calcium phosphate discs. Eur Cells Mater (2015) 29:314-29.

[29] Sheikh Z, Abdallah MN, Hanafi AA, Misbahuddin S, et al. Mechanisms of in vivo degradation and resorption of calcium phosphate based biomaterials. Materials (2015) 8:7913-25.

[30] Davison NL, ten Harkel B, Schoenmaker T, et al. Osteoclast resorption of beta-tricalcium phosphate controlled by surface architecture. Biomaterials (2014) 35:7441-51.

[31] Välimäki VV, Aro HT. Molecular basis for action of bioactive glasses as bone graft substitute. Scand J Surg (2006) 95:95-102.

[32] Walsh W, Christou C, Low A, Yu Y, et al. Bone graft materials: a comparison of NanOss Bioactive 3d and VitOss BA in a challenging model. Bone Joint J (2013) 95-B(Supp. 15):359.

[33] Epstein NE. Beta tricalcium phosphate: observation of use in 100 posterolateral lumbar instrumented fusions. Spine J (2009) 9:630-8.

[34] Epstein NE. Preliminary documentation of the comparable efficacy of VitOss versus NanOss bioactive as bone graft expanders for posterior cervical fusion. Surg Neurol Int (2015) 6:S164-S171. 
Page 15 of 30

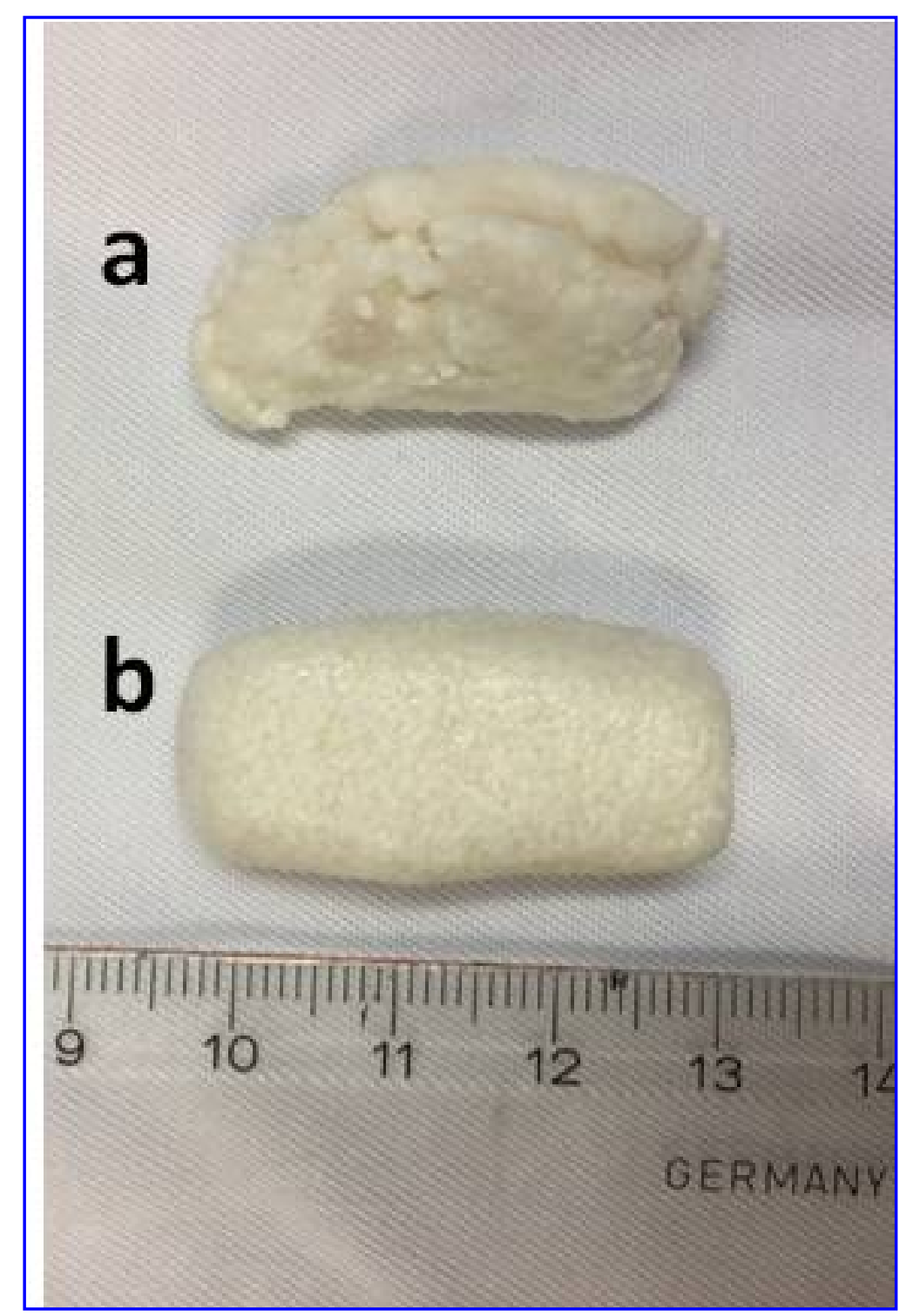

Figure 1. (a) Spinal sample $(5 \mathrm{cc})$ of $\mathrm{CaP} / \mathrm{BG} / \mathrm{C}$ composite after preparing it following the manufacturer's indications, cutting into the desired volume and shaping. (b) Spinal sample $(5 \mathrm{cc})$ of CaP/AOC after shaping. 


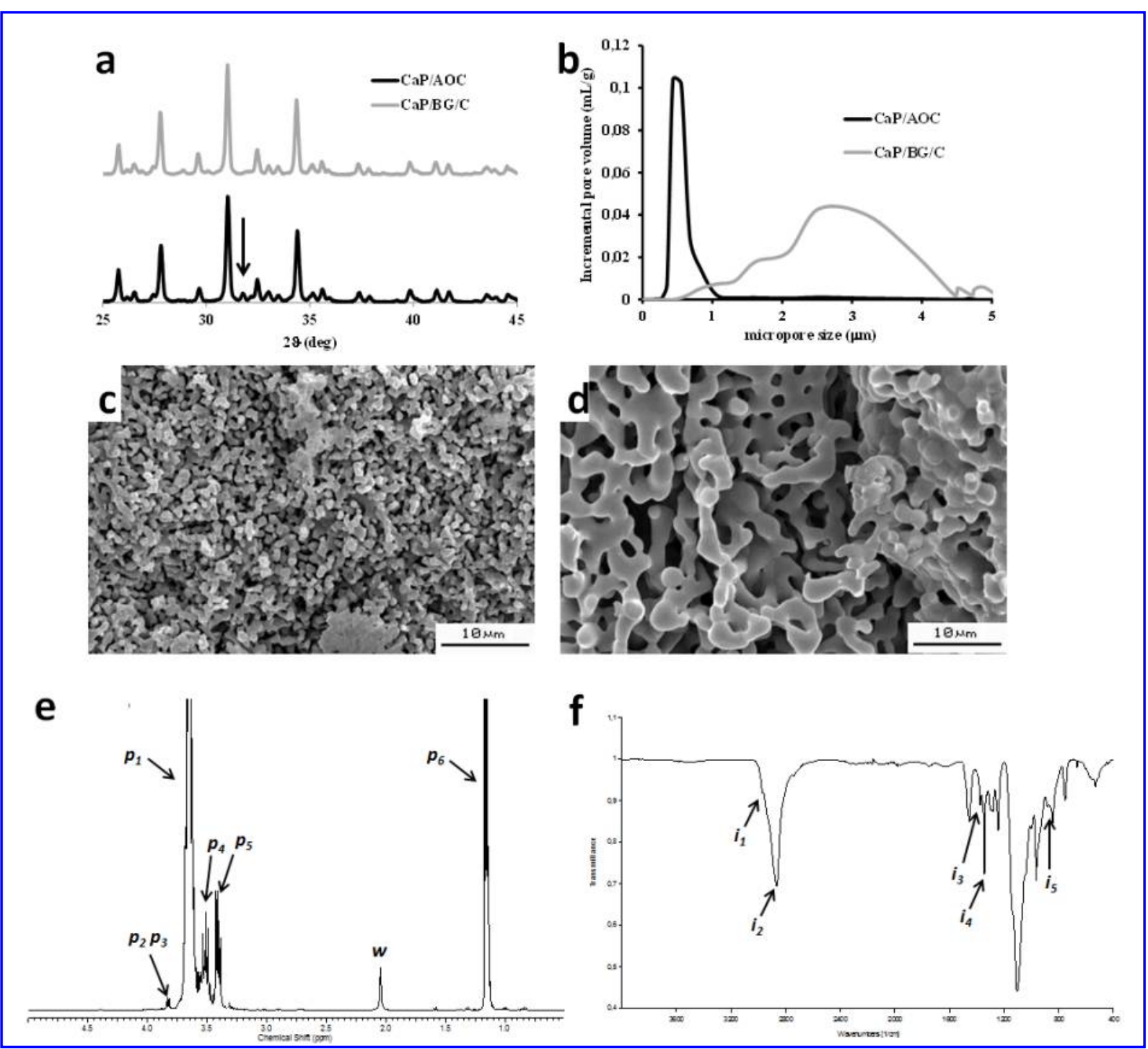

Figure 2. (a) XRD patterns showing the chemistry of the calcium phosphate phase in the two materials: the arrow indicates the peak of HA in the biphasic composition of the ceramic component in CaP/AOC composite. (b) Volume distribution of micro-/nano- pores within the calcium phosphate phases of $\mathrm{CaP} / \mathrm{AOC}$ and $\mathrm{CaP} / \mathrm{BG} / \mathrm{C}$ materials. SEM images showing the different surface submicron- and micron- structure of the calcium phosphate phases of (c) $\mathrm{CaP} / \mathrm{AOC}$ and (d) $\mathrm{CaP} / \mathrm{BG} / \mathrm{C}$. (e) ${ }^{1 \mathrm{H}} \mathrm{NMR}$ of the AOC extracted from CaP/AOC showing that it is composed of two different polymer components, namely poly(ethylene glycol) (PEG) and poly(propylene glycol) (PPG). The typical NMR shifts of each component are indicated as $p_{1}(3.60-3.75 \mathrm{ppm}, \mathrm{PEG}), p_{2}$ and $p_{3}$ (3.853.95 ppm, PPG), $p_{4}\left(3.50-3.60\right.$ ppm, PPG), $p_{5}\left(3.40-3.50\right.$ ppm, PPG) and $p_{6}(1.10-1.20$ ppm, PPG). The symbol $w$ indicates the shift for water. (f) ATR-FTIR spectra of the AOC extracted from CaP/AOC confirming that AOC is a copolymer, or a mixture, of PEG and PPG. The typical vibrational bands for PEG and PPG are indicated as 
$i_{1}\left(2970-2971 \mathrm{~cm}^{-1}, \mathrm{PPG}\right), i_{2}\left(2882-2891 \mathrm{~cm}^{-1}, \mathrm{PEG}\right), i_{3}\left(1375-1373 \mathrm{~cm}^{-1}, \mathrm{PPG}\right), i_{4}\left(1341-1352 \mathrm{~cm}^{-1}, \mathrm{PEG}\right)$ and $i_{5}$ (860-875 $\left.\mathrm{cm}^{-1}, \mathrm{PPG}\right)$. All the other bands present on the spectra are in common for PEG and PPG. 


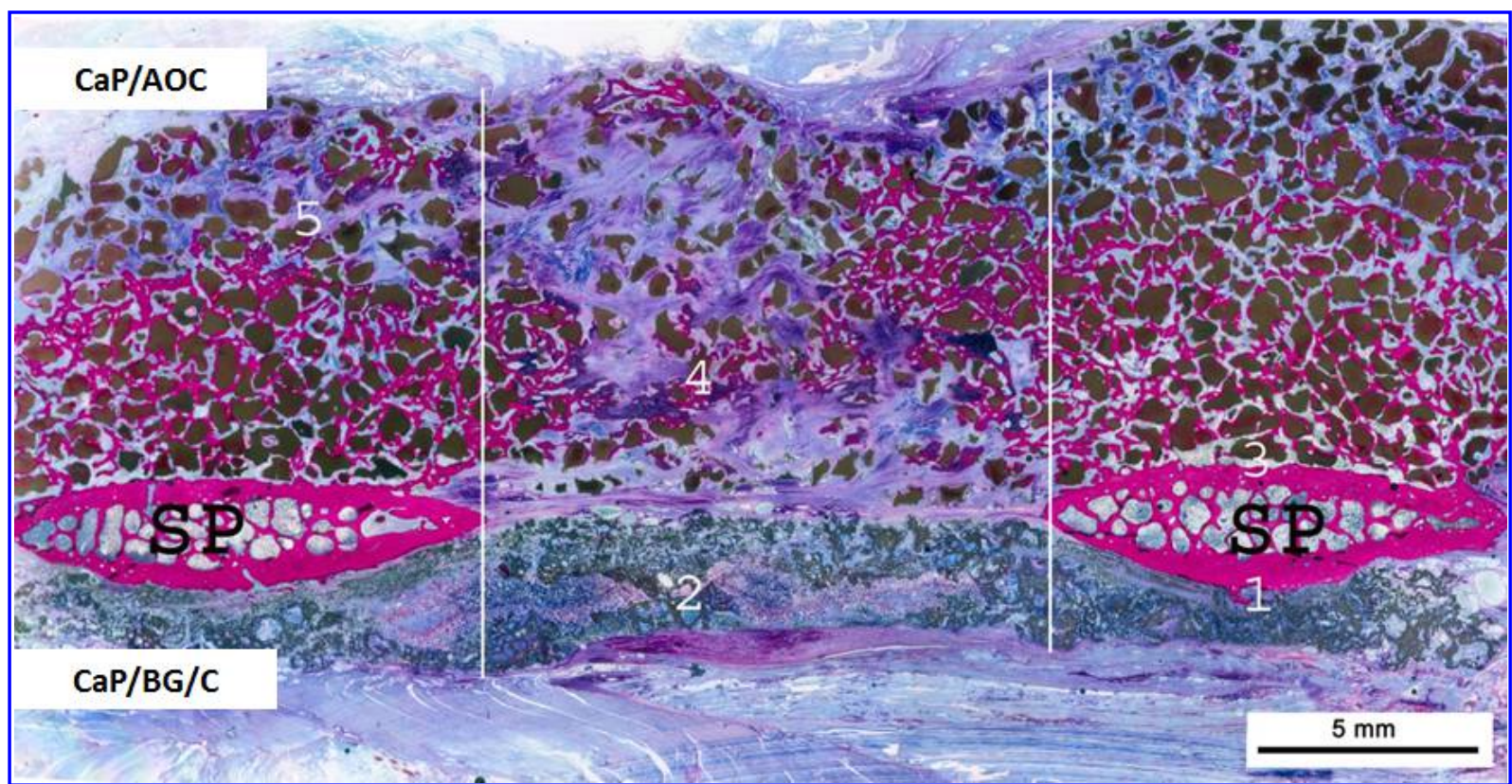

Figure 3. A histological overview (coronal plane) of CaP/AOC (upper) and CaP/BG/C (down) implanted in the spine region of dog for 12 weeks, showing bone formation in $\mathrm{CaP} / \mathrm{AOC}$ and no bone in CaP/BG/C (nondecalcified section; $1 \%$ methylene blue and $0.3 \%$ basic fuchsin staining; SP: spinous process; the region between the lines is the region of interest for histomorphometrical evaluation regarding bone formation and ceramic resorption). The numbers 1 to 5 on the slide indicate the regions whose details are shown at higher magnification in Figures 4 to 8. 


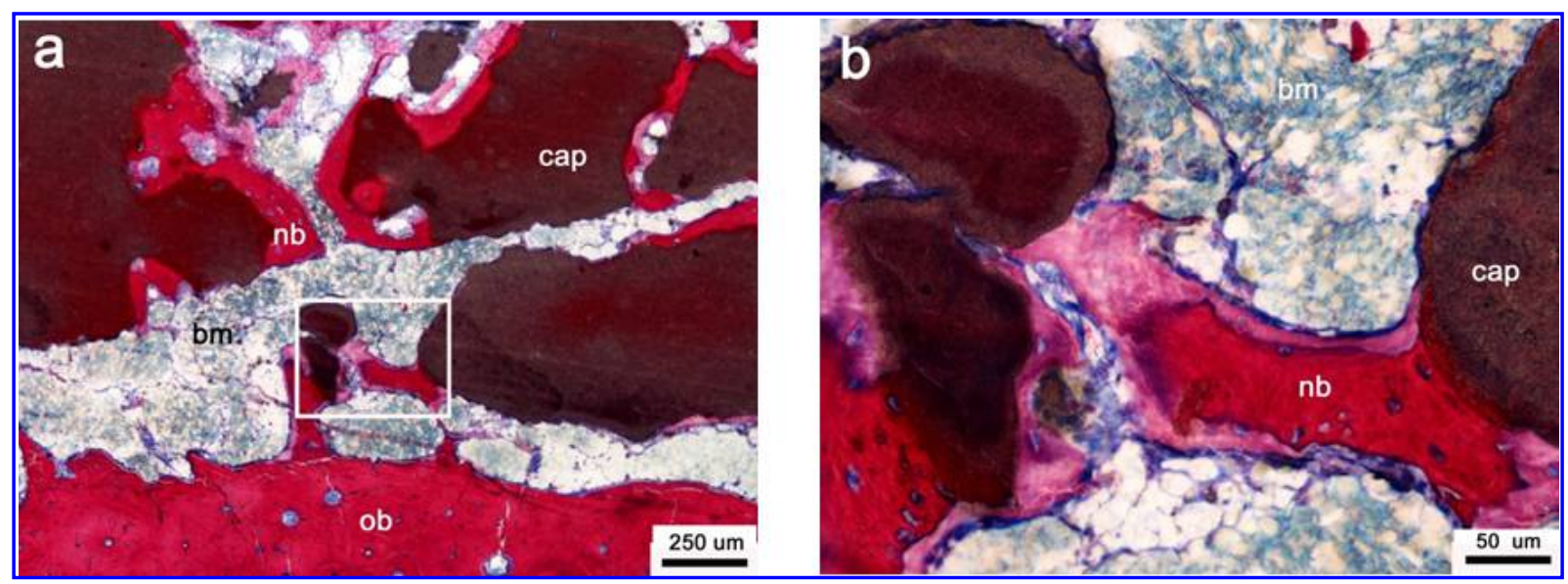

Figure 4. (a) A light microscopic observation of site 3 in Figure 3 showing bone formation in $\mathrm{CaP} / \mathrm{AOC}$ implants nearby the spinous process, and (b) represents the square in (a) at a higher magnification, showing mineralized bone, osteoid and bone marrow (cap: calcium phosphate ceramic, nb: new bone; ob: host bone; bm: bone marrow). 


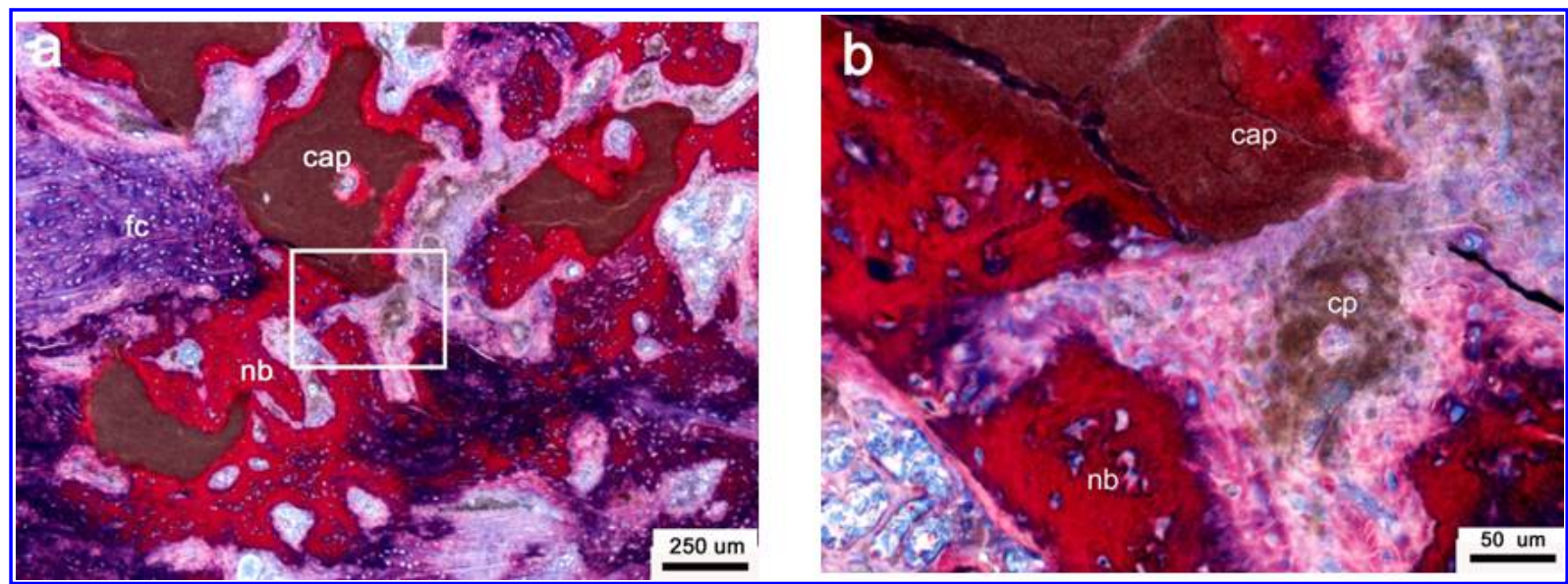

Figure 5. (a) A light microscopic observation of site 4 in Figure 3 showing the tissue response to CaP/AOC implants in the region between the two spinous processes, and (b) is the square in (a) at a higher magnification, showing calcium phosphate ceramic resorption and bone formation in CaP/AOC implants (cap: calcium phosphate ceramic; nb: new bone; fc: fibrous cartilage; cp: ceramic particulate). 


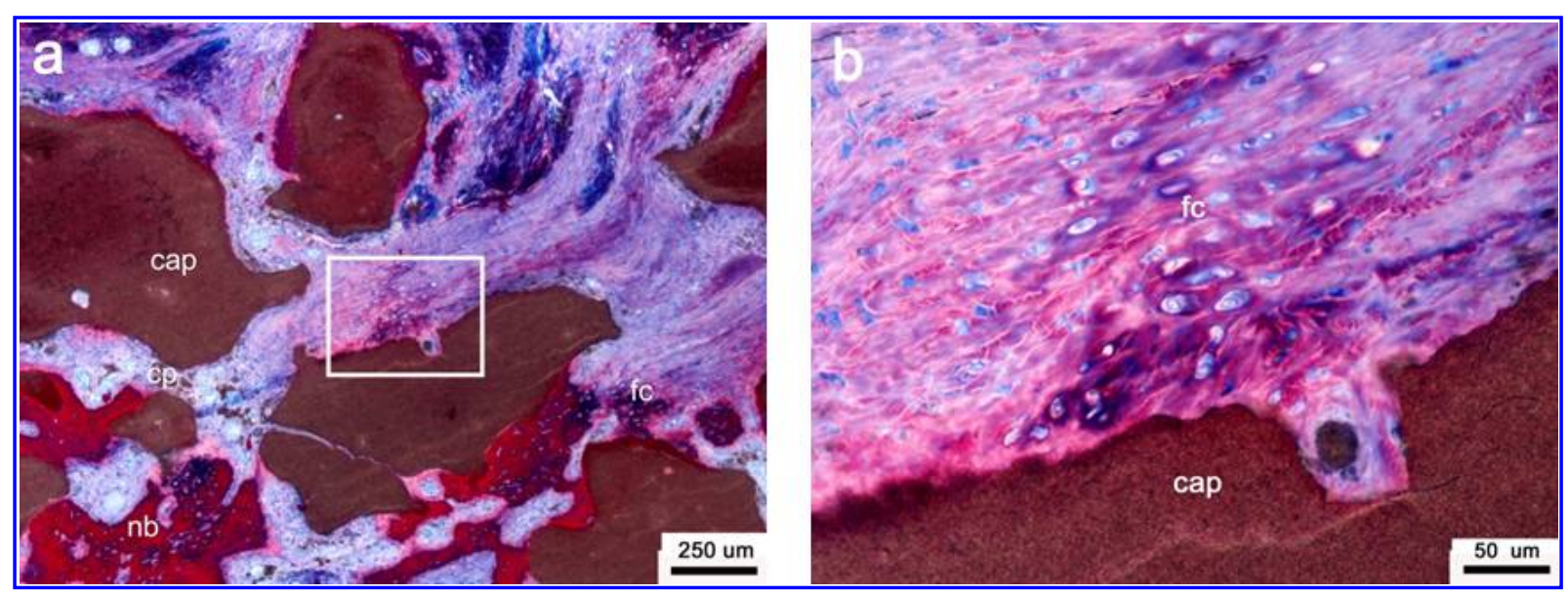

Figure 6. (a) A light microscopic observation of site 5 in Figure 3 showing the tissue response to CaP/AOC in the region far from the host bone beds and (b) is the selected square in (a) at a higher magnification, showing fibrous cartilage (cap: calcium phosphate ceramic; nb: new bone; fc: fibrous cartilage; cp: ceramic particulate). 


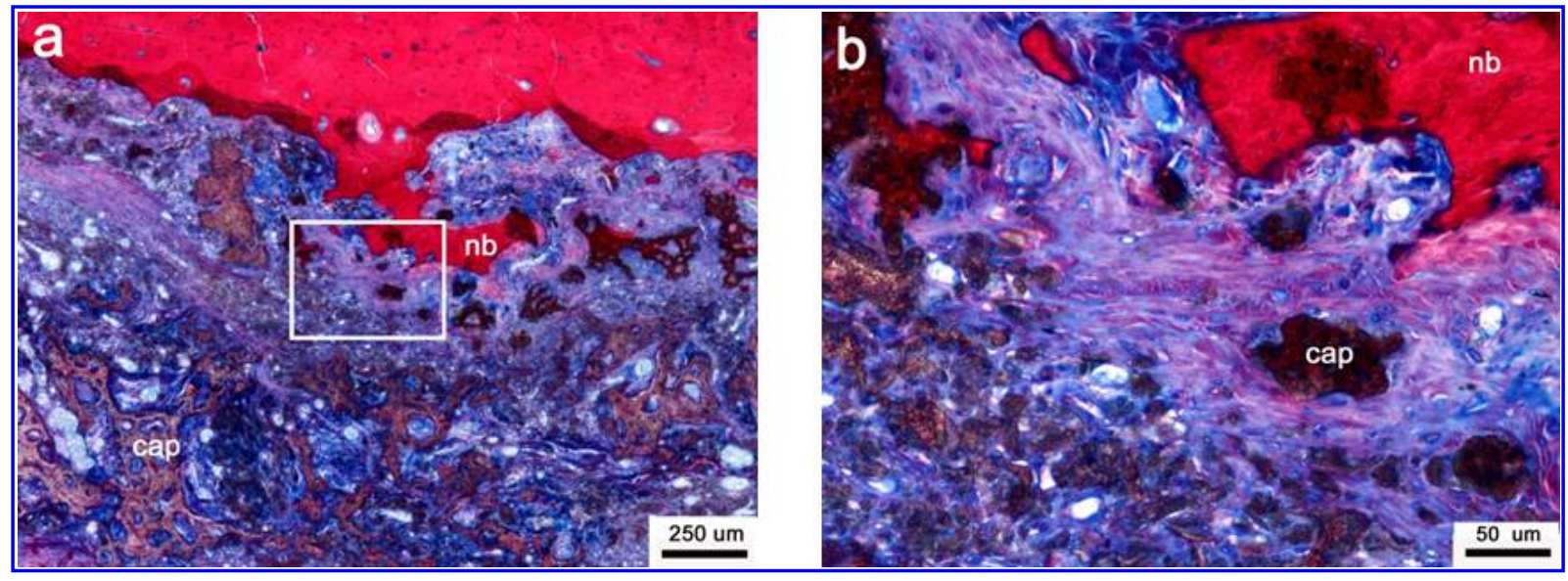

Figure 7. (a) Site 1 in Figure 3 at a higher magnification, showing limit conductive bone formation in $\mathrm{CaP} / \mathrm{BG} / \mathrm{C}$ from the spinous process and (b) is the square in (a) at a higher magnification, showing fibrous tissues, ceramic fragment (cap: calcium phosphate ceramic; nb: new bone). 


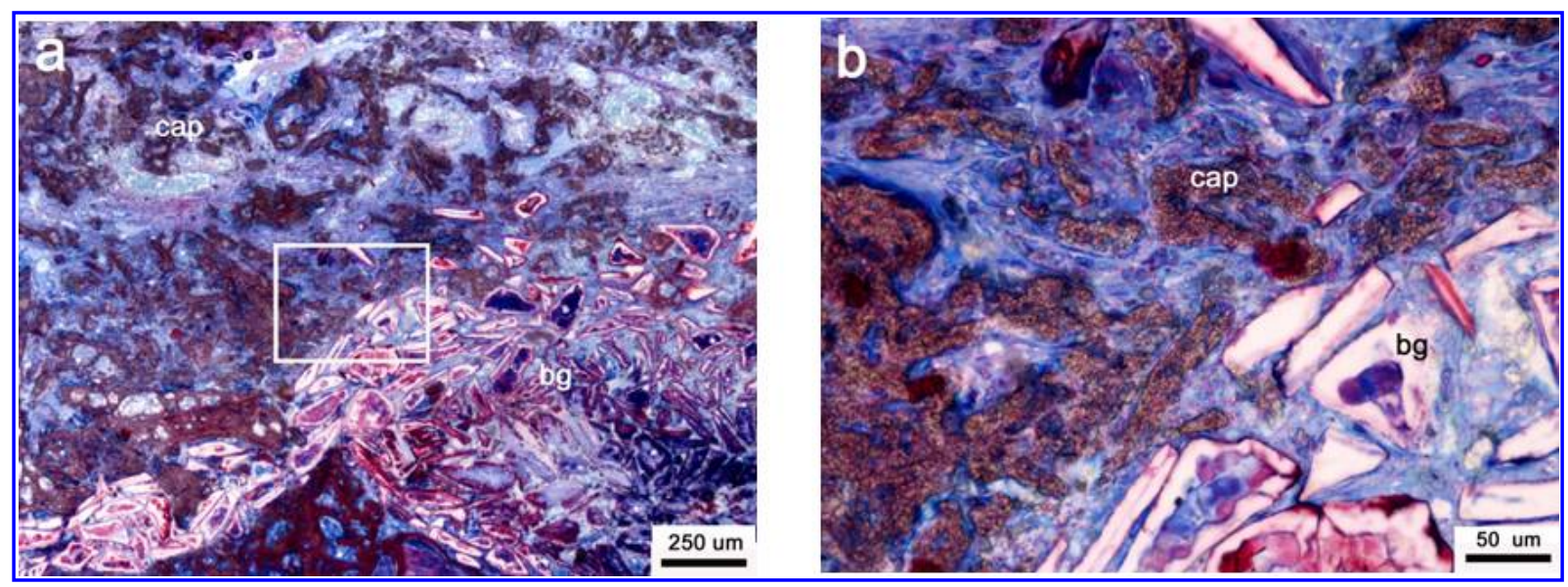

Figure 8. (a) A light microscopic observation of site 2 in Figure 3 showing the tissue response to $\mathrm{CaP} / \mathrm{BG} / \mathrm{C}$ in the region between the two spinous processes and (b) is the square in (a) at a higher magnification, showing tissue responses to calcium phosphate ceramic particle and BioGlass ${ }^{\mathrm{TM}}$ particles respectively (cap: calcium phosphate ceramic; bg: BioGlass ${ }^{\mathrm{TM}}$ ). 


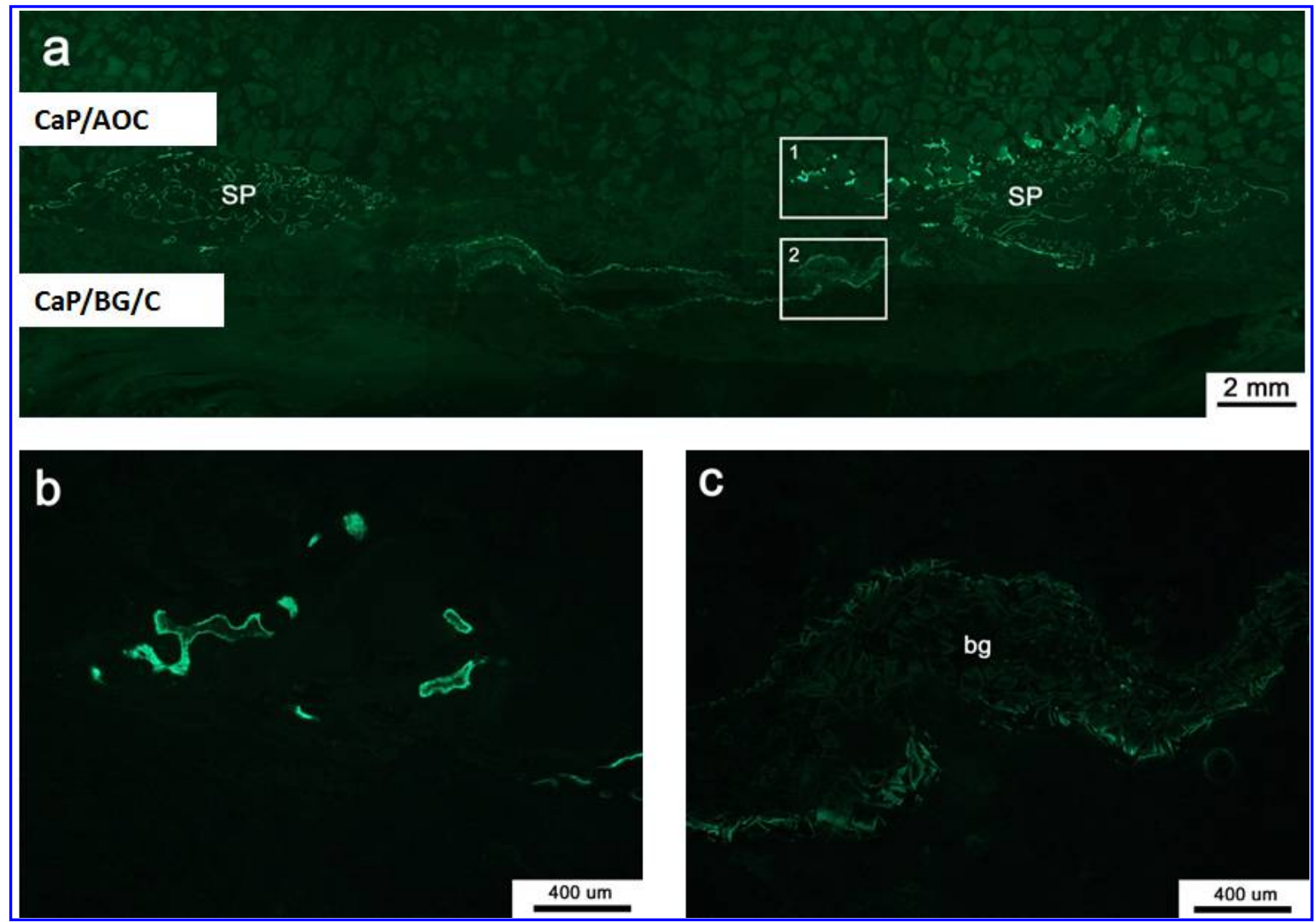

Figure 9. Fluorescent observations of spinal implants. (a) An overview observation; (b) is the square 1 in (a) at a higher magnification showing bone formation nearby the spinous processes within the CaP/AOC implants at week 6 and (c) is the square 2 in (a) at the high magnification showing mineralization of BioGlass ${ }^{\mathrm{TM}}$ within CaP/BG/C implants (SP: spinous process; bg: BioGlass ${ }^{\mathrm{TM}}$ ). 


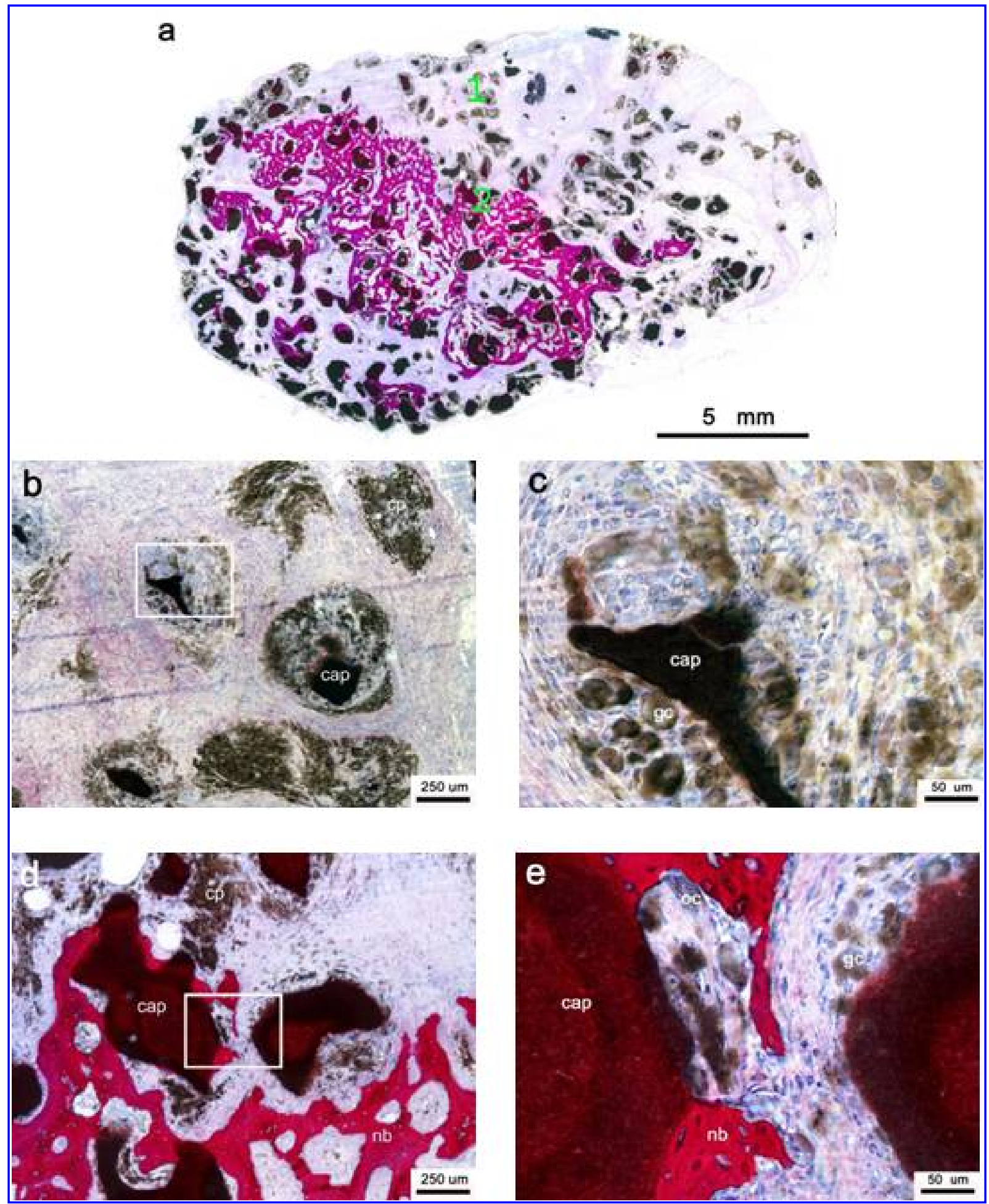

Figure 10. Histology of CaP/AOC implanted in muscle of dogs for 12 weeks. (a) A histological overview, (b) site 1 in (a) at a higher magnification, showing the degradation of calcium phosphate ceramic, (c) Square in (b) at a higher magnification, showing the degradation process of calcium phosphate ceramic, (d) site 2 in (a) at a higher magnification, showing bone formation and degradation of calcium phosphate ceramic, (e) the square in 
(d) at a higher magnification, showing bone remodeling and degradation of calcium phosphate ceramic (undecalcified section; $1 \%$ methylene blue and $0.3 \%$ basic fuchsin staining; cap: calcium phosphate ceramic; gc: giant cell; cp: ceramic particulate, nb: new bone; oc: osteclast). 


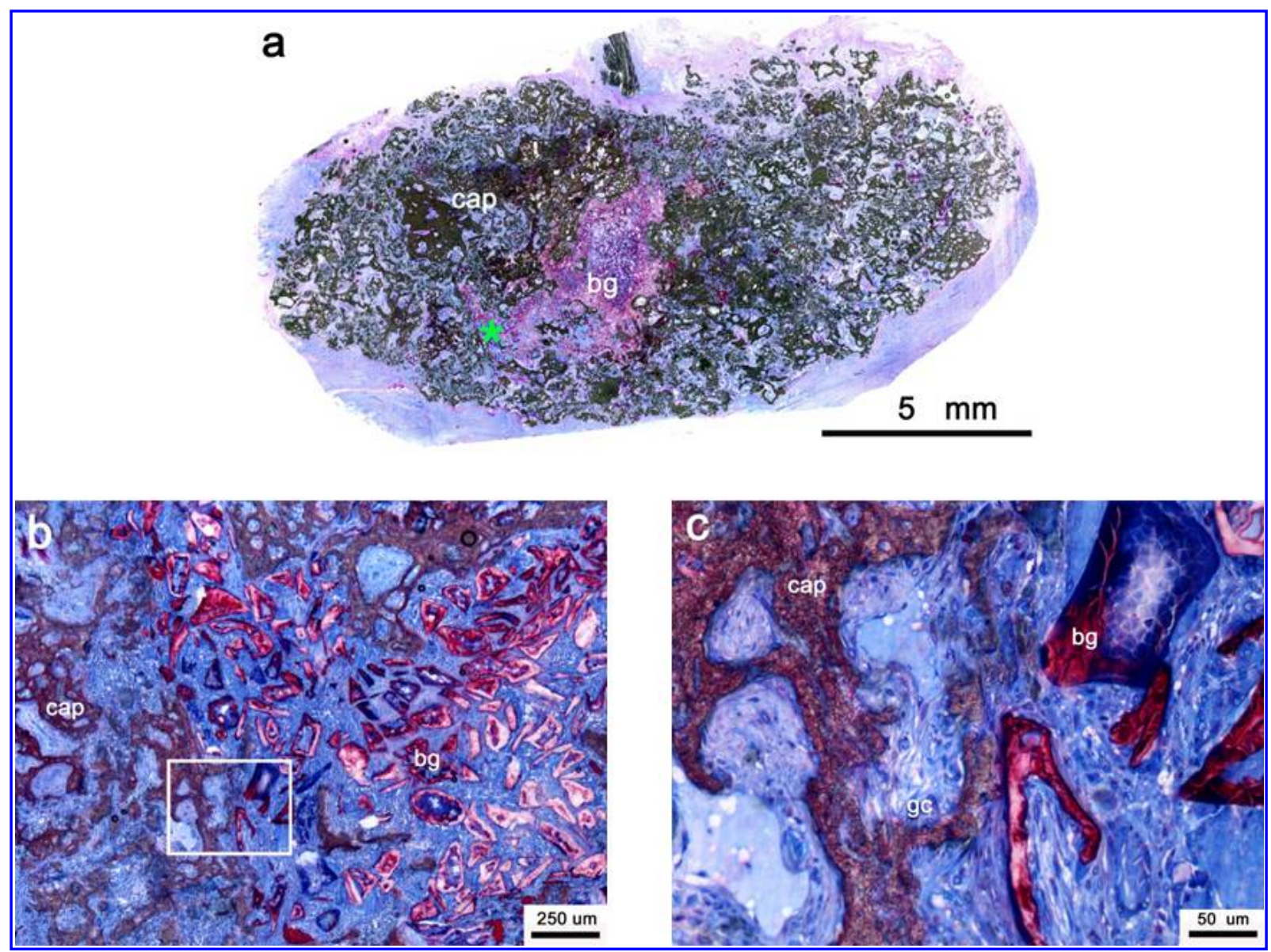

Figure 11. Histology of $\mathrm{CaP} / \mathrm{BG} / \mathrm{C}$ after intramuscular implantation in dog for 12 weeks. (a) A histological overview, (b) site marked with green star in (a) at a higher magnification, showing the presence of $\mathrm{CaP}$ ceramic particles and BioGlass ${ }^{\mathrm{TM}}$ particles but no bone; (c) the square in (b) at a higher magnification, showing fibrous tissues and foreign body giant cells in the implants (non-decalcified section; $1 \%$ methylene blue and $0.3 \%$ basic fuchsin staining; cap: calcium phosphate ceramic; bg: BioGlass ${ }^{\mathrm{TM}}$; gc: giant cell). 


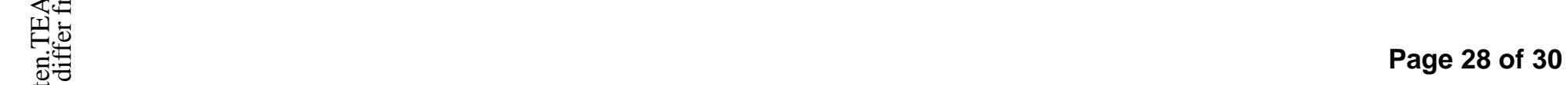

Table 1. General summary of the two synthetic bone grafts.

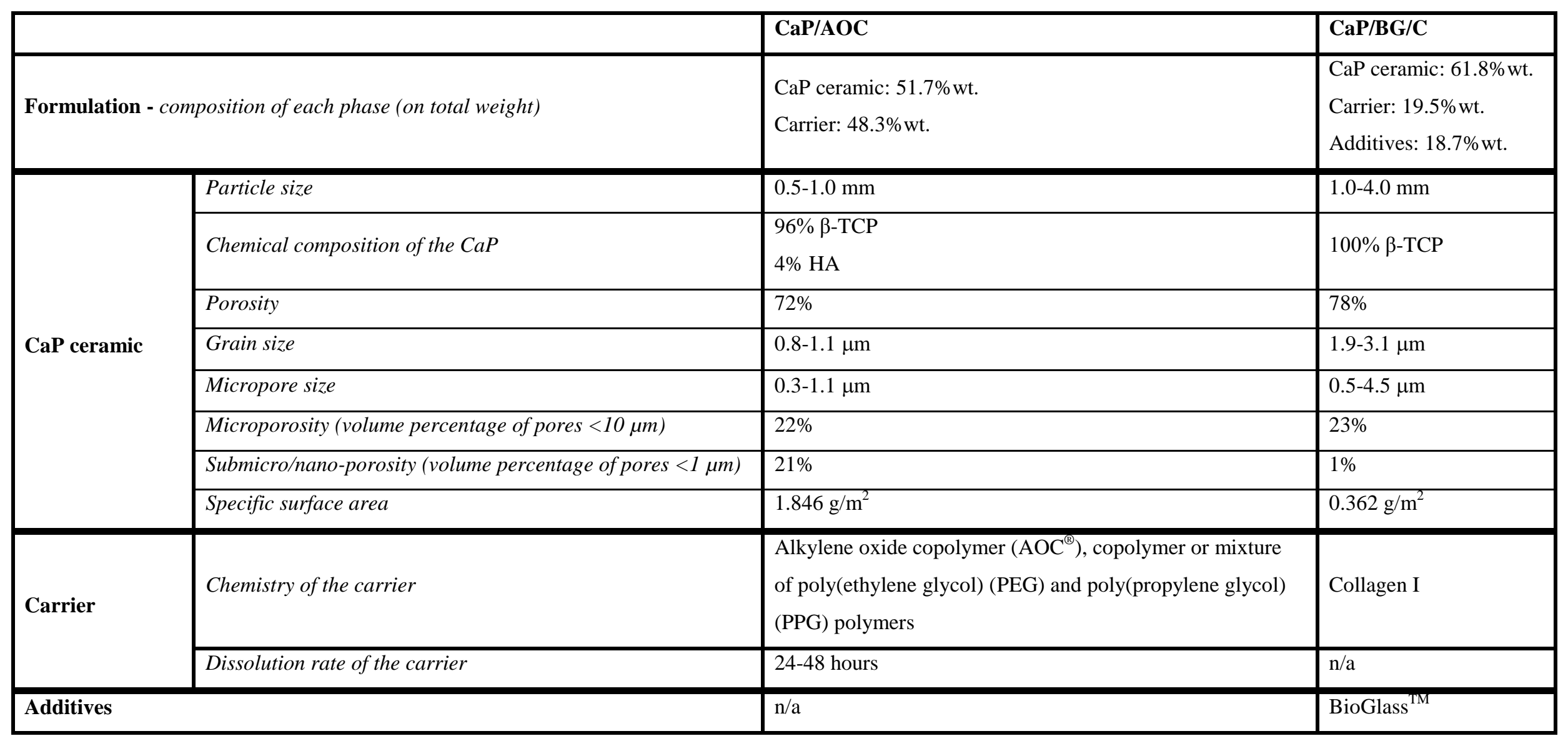




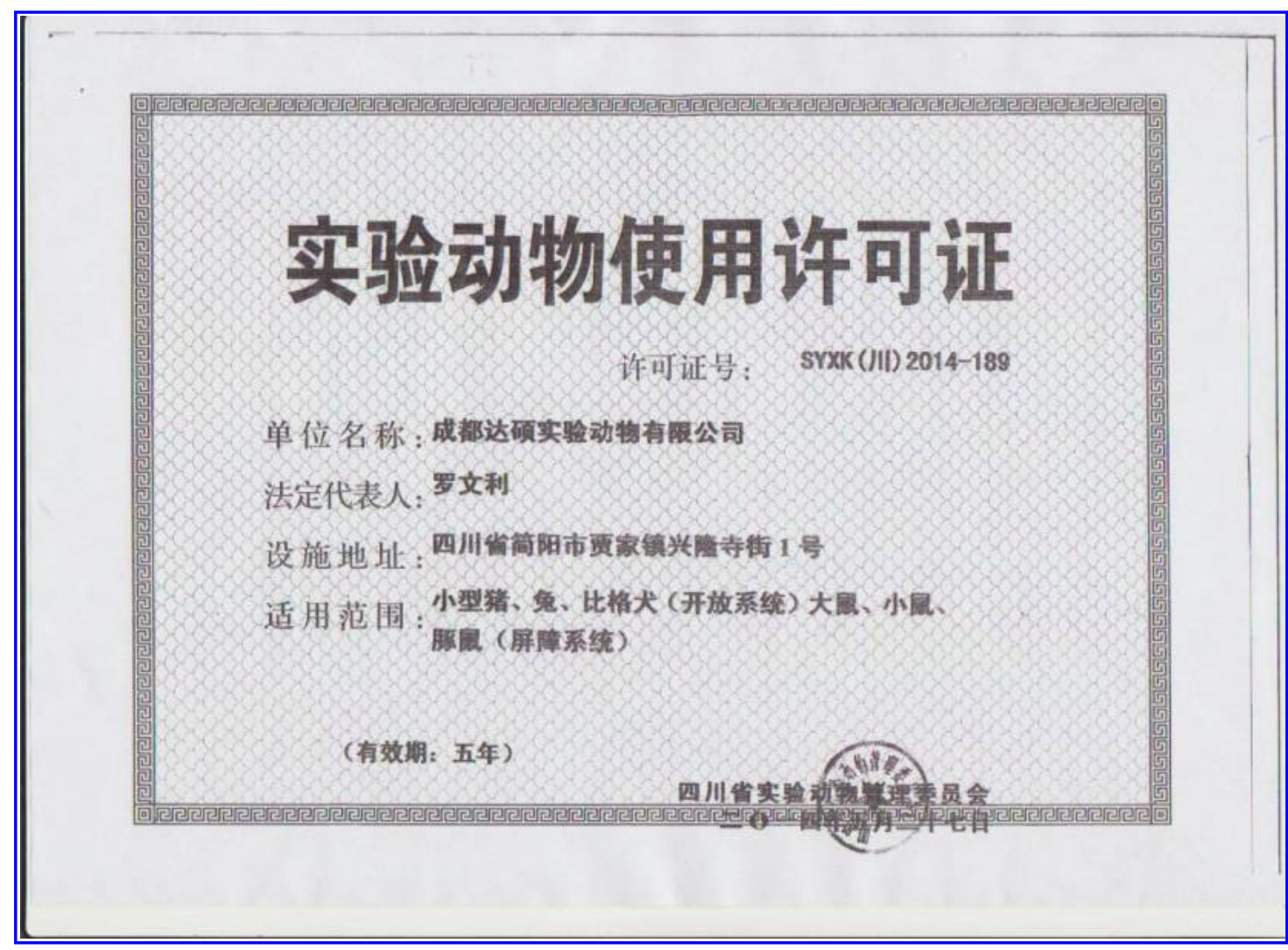

\section{License of Usage of Experimental Animals}

License number: SYXK (CHUAN) 2014-189

Department: Chengdu Dossy Experimental Animals Co. Ltd.

Legal representative: Wenli Luo

Address: Xinglong Si street 1, Jiajia town, Jianyang city, Sichuan province, China

Range of application: minipigs, rabbits, dogs (open system), rats, mice, guinea pigs (barrier system)

Period of validity: Five years

Issuing authority:

The experimental animals management committee of Sichuan province

Date: 11 April 2014 